\title{
Do earthworms stimulate enhanced weathering? Results from a mesocosm experiment.
}

\author{
ARTHUR VIENNE ${ }^{1}$, SILVIA POBLADOR IBANEZ ${ }^{2}$ AND \\ SARA VICCA ${ }^{1}$ \\ ${ }^{1}$ University of Antwerp \\ ${ }^{2}$ UAntwerpen \\ Presenting Author: arthur.vienne@uantwerpen.be
}

Do earthworms stimulate enhanced weathering? Results from a mesocosm experiment.

Arthur Vienne, Silvia Poblador, Sara Vicca

Plants and Ecosystems (PLECO), Biology Department, University of Antwerp, Universiteitsplein 1, 2610 Wilrijk, Belgium

Earthworms are important ecosystem engineers that contribute to mineral weathering through the mechanical disintegration of particles. Mineral grains are ground as they pass through an earthworm intestine. Besides physical weathering, earthworms can also alter silicate minerals through chemical weathering. In this context, previous research found that basalt weathering rates were accelerated by marine earthworms. However, quantitative data on the influence of earthworms on $\mathrm{C}$ sequestration via enhanced weathering is still lacking.

We set up a mesocosm experiment to verify the influence of earthworms on $\mathrm{C}$ sequestration through enhanced weathering. Twenty-eight mesocosms were filled with soil with or without basalt (100 ton/ha). Four earthworm treatments were established: no earthworms, 30 anecic worms (Lumbricus terrestris), 30 endogeic worms (aporectodea caliginosa) or 15 worms of each of these two species. Mesocosms were watered regularly to enable soil pore water and leachate sampling. Preliminary data indicate a significant earthworm effect on weathering rates.

Furthermore, effects of earthworms and basalt on soil respiration are investigated and worm casts and soil aggregates will be analysed to obtain more insights into the underlying mechanisms of the earthworm effect on enhanced weathering. Finally, nitrogen leaching and $\mathrm{N}_{2} \mathrm{O}$ emissions are investigated, as earthworm activity can increase $\mathrm{N}_{2} \mathrm{O}$ emissions in the anaerobic environments of their casts. An increase in soil $\mathrm{pH}$ due to EW might thus reduce $\mathrm{N}_{2} \mathrm{O}$ emissions by facilitating complete denitrification processes. The results of the combined effect of basalt addition and potential interactions with earthworms will be presented.

Overall, this study shows the effects of earthworms on soil $\mathrm{C}$ sequestration via enhanced weathering and on $\mathrm{N}_{2} \mathrm{O}$ emissions to the atmosphere. 